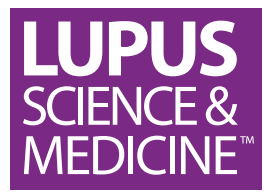

\title{
Peripheral neuropathy in systemic lupus erythematosus: what can neuromuscular ultrasonography (NMUS) tell us? A cross-sectional study
}

To cite: Mahran SA, Galluccio F, Khedr TM, et al. Peripheral neuropathy in systemic lupus erythematosus: what can neuromuscular ultrasonography (NMUS) tell us? A cross-sectional study. Lupus Science \& Medicine 2021;8:e000521. doi:10.1136/ lupus-2021-000521

SAM and FG contributed equally.

Received 6 May 2021

Accepted 18 June 2021
Check for updates

(C) Author(s) (or their employer(s)) 2021. Re-use permitted under CC BY-NC. No commercial re-use. See rights and permissions. Published by BMJ.

For numbered affiliations see end of article.

Correspondence to

Dr Felice Galluccio;

felicegalluccio@gmail.com

Safaa A Mahran, ${ }^{1}$ Felice Galluccio (D) , ,3 Tayseer Mohamed Khedr, ${ }^{1}$ Amira Elsonbaty, ${ }^{1}$ Abdallah El-Sayed Allam,, ${ }^{3,4}$ Alvaro Garcia Martos, ${ }^{5}$ Doaa M M Osman, ${ }^{6}$ Marco Matucci-Cerinic (D) , '7 Serena Guiducci, ${ }^{2,7}$ Marwa A A Galal ${ }^{1}$

\section{ABSTRACT}

Objective To evaluate peripheral nerve involvement in patients with SLE with neuromuscular ultrasonography (NMUS) and understand its role in investigating SLErelated peripheral neuropathy.

Methods This is an observational cross-sectional study on patients with SLE and healthy controls. Five nerves in each patient were examined bilaterally with NMUS, and the cross-sectional area (CSA) of each nerve at certain sites was estimated. The mean CSA at each site, for each nerve, in each group was statistically analysed and compared between groups.

Results 370 nerves were evaluated in 37 patients. By nerve conduction study (NCS), 36 patients had polyneuropathy ( $80.6 \%$ mixed type, $19.4 \%$ sensory). Significant mean CSA enlargement was present among the ulnar nerve at the Guyon's canal and mid-humerus (both $p=0.001$ ); tibial nerve at the distal leg and proximal to the tarsal tunnel $(p=0.003$ and $p=0.001$, respectively); and peroneal nerve at the popliteal fossa $(p=0.042)$. The mean CSA showed high specificity compared with NCS.

Conclusion Our study shows that CSA could be a complementary tool to NCS for studying peripheral neuropathy in SLE. Furthermore, NMUS provides data on the different pathophysiological aspects of nerve involvement in SLE. Future studies using more than one sonographic parameter in combination with NCS and nerve histopathology are recommended to further investigate SLE-related neuropathy.

Trial registration number NCT04527172.

\section{INTRODUCTION}

SLE is a chronic autoimmune connective tissue disease with multisystem involvement, including the central and peripheral nervous systems. ${ }^{1}$ Its worldwide prevalence ranges from 0.3 to 23 per 100000 persons per year. ${ }^{2}$

Peripheral neuropathy (PN) is not uncommon in SLE and includes mononeuropathy, mononeuritis multiplex, polyneuropathy and/or cranial neuropathy. ${ }^{34}$

\section{Key messages}

What is already known about this subject?

- Polyneuropathy is the most frequent subtype of peripheral nerve involvement in SLE.

- Nerve conduction study (NCS) and neuromuscular ultrasonography (NMUS) detect functional and morphological changes of nerves, respectively.

What does this study add?

- Ultrasound measurement of the cross-sectional area of the peripheral nerves in SLE has high specificity and is repeatable, low cost and risk-free and more patient-friendly than NCS.

How might this impact on clinical practice or future developments?

- The combination of NCS and NMUS provides a more detailed idea of the nerve changes in SLE.

- NMUS could become an excellent screening test for evaluation of peripheral neuropathy in SLE.

In the last decades, the use of the neuromuscular ultrasonography (NMUS) to evaluate the different types of neuropathies has gained much attention. ${ }^{5-10}$ It is a dynamic, noninvasive, bedside tool with low interobserver reliability when used in multiple centres. When compared with MRI, NMUS was found to be a more sensitive, equally specific and less expensive tool in identifying multifocal nerve lesions. ${ }^{11}$ Accordingly, NMUS might become a helpful tool in diagnosing PN especially when combined with electrodiagnosis (EDX). Many studies were performed on different types of PN using NMUS, including chronic inflammatory demyelinating polyneuropathy, Guillain-Barré syndrome, axonal neuropathies, vasculitis, diabetes and sarcoidosis. ${ }^{8-13}$

Most of the authors concluded that NMUS facilitated the assessment of the nerves by 
evaluating certain parameters, including the nerve size (using nerve cross-sectional area, CSA), echogenicity, mobility and vascularity. It facilitates recognition of the underlying local cause in entrapment neuropathies. ${ }^{12-14}$ Nevertheless, it helps in the discrimination between demyelinating and axonal neuropathy, especially when clinical diagnosis and EDX are inconclusive. ${ }^{14}$

According to our knowledge, no previous study has investigated the morphological features of PN related to SLE. Thus, our work aimed to evaluate peripheral nerve involvement in patients with SLE using NMUS and to find out what can NMUS add to traditional electrophysiological studies in investigating SLE-related PN.

\section{METHODS}

\section{Subjects}

Forty-one patients with SLE fulfilling the Systemic Lupus International Collaborating Clinics classification criteria ${ }^{4}$ were collected from the outpatient clinic of the Department of Rheumatology and Rehabilitation, Assiut University Hospitals, and enrolled in this observational crosssectional study. Twenty age-matched and sex-matched healthy subjects were included in the study as healthy controls. Patients were excluded from the study if an obvious cause of PN was found as degenerative, diabetic, traumatic, infectious, toxic or drug-induced PN.

Written informed consent was obtained from every subject included in the study.

Basic demographic data and clinical history were collected from patients' medical files.

All patients underwent clinical evaluation by expert rheumatologists, including full systemic and neurological examinations at the time of presentation. Laboratory work included complete blood count, erythrocyte sedimentation rate, liver and kidney function tests, serum electrolytes, urine analysis, 24-hour urine protein, creatinine clearance, and lipid profile. Serum autoantibodies such as ANA, anti-dsDNA, C3 and C4 were measured in all patients with SLE.

Two further investigations were applied to the subjects on the same day: electroneurophysiological study and peripheral nerve ultrasonography.

\section{Electrodiagnosis}

Using an electroneurophysiological device (NIHON KOHDEN Neuropack M1, MEB-9200 electromyography unit, four channels), nerve conduction study (NCS) was carried out on the median, ulnar, tibial, common peroneal and sural nerves bilaterally. The F-wave study was done for the median, ulnar and tibial nerves. Surface stimulating and recording electrodes were used. According to the results of EDX, the examined nerves were grouped into nerves with normal EDX and those with abnormal EDX, which was further subdivided into axonal and demyelinated PN (according to reference values in the literature). ${ }^{15}$

\section{Neuromuscular ultrasonography}

Peripheral nerves ultrasonography examination was carried out using a high-end machine (MyLab Seven eHD; Esaote, Italy) with linear array (6-13 MHz/11-18 MHz) transducers on the same nerves examined by EDX. The suitable machine presets for superficial and deep nerves were used. Ultrasonography scan was done at standardised anatomical points as follows: median nerve: proximally (at the axilla), mid-humerus (midpoint between the greater tuberosity and the antecubital fossa), distally at the mid-forearm (midpoint between the ulnar styloid process and the medial epicondyle of the humerus) and the carpal tunnel inlet (at the level of the pisiform bone); ulnar nerve: proximally (at the axilla), mid-humerus, at the mid-forearm (distal) and Guyon's canal; tibial nerve: proximally (within popliteal space), distally $(5 \mathrm{~cm}$ above the medial malleolus) and at the tarsal tunnel; common peroneal nerve: proximally (within the popliteal space) and at the fibular neck; deep peroneal nerve at the ankle; and finally sural nerve: $14 \mathrm{~cm}$ proximal to the lateral malleolus.

Subjects were examined in a resting supine position with the arm supinated, abducted and supported at the body level. Lower limbs were examined in both supine and prone positions (to scan the popliteal fossa and the sural nerve). The probe was applied without pressure (only the weight of the probe) and was kept perpendicular to the nerve to obtain an optimum image of the nerve. The nerves were scanned in axial planes, and the CSA of each nerve was measured just inside the hyperechoic rim of the epineurium at the same anatomical points on both sides (figures 1 and 2).

Abnormal CSA was considered if it exceeded the mean CSA +2 SD of healthy controls at the same point.

The ultrasonographic examination was performed and reported by an expert rheumatologist, and the images were then further evaluated (offline) by another expert rheumatologist who was blinded to both clinical and electrophysiological data of the patients. Any conflict in reporting was referred to a third expert rheumatologist to provide the final decision.

\section{Statistics}

IBM SPSS Statistics V.20 was used for statistical analysis. Mean \pm SD were used to describe most of the quantitative data, while for summarising the qualitative data frequency and per cent were used.

All quantitative data have been tested for normal distribution. Accordingly, Student's t-test and one-way analysis of variance were used; Mann-Whitney and Kruskal-Wallis tests were also applied when appropriate. For categorical data, $\chi^{2}$ test was used to compare the significance between different proportions. $\mathrm{P}<0.05$ was considered statistically significant.

Receiver operating characteristic (ROC) curve and cross-tabulation were also used to find the benefit of using NMUS instead of EDX in detecting PN affection in patients with SLE. 

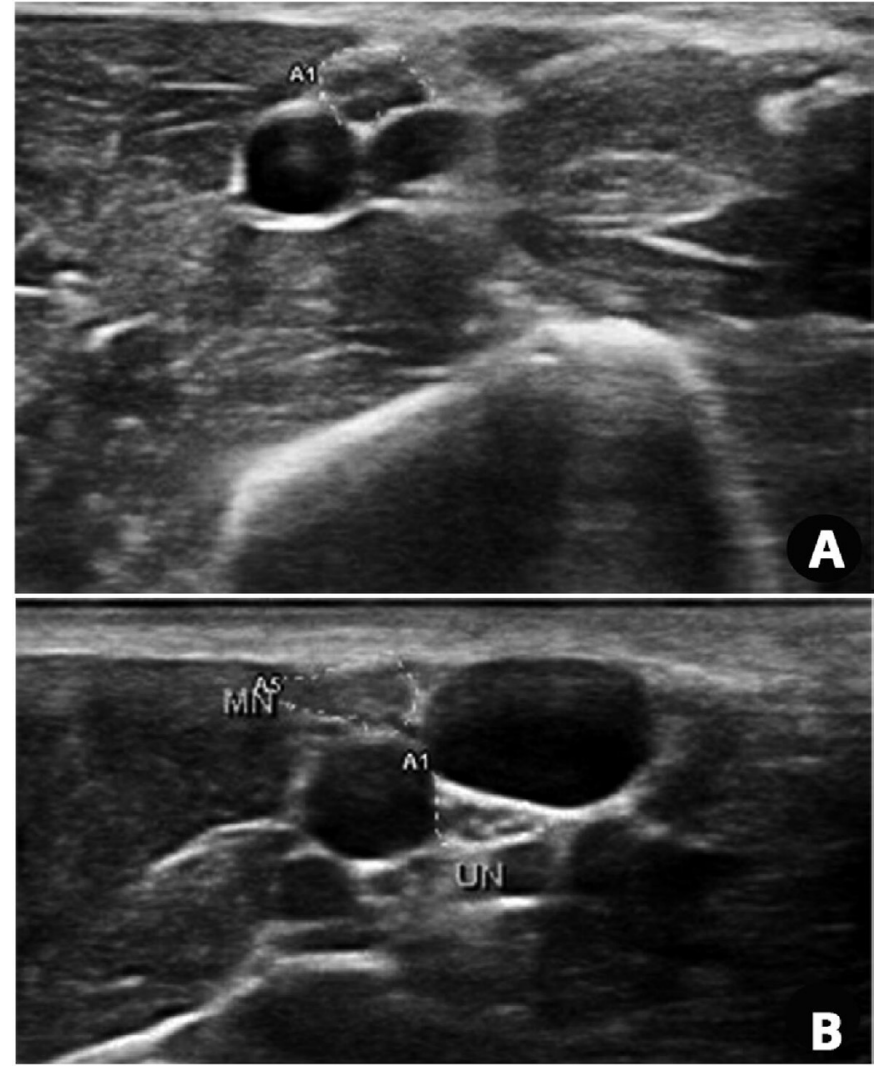

Figure 1 Neuromuscular ultrasonography showing axial views and cross-sectional area of the examined nerves: $(A)$ median nerve at the mid-humerus measuring $10 \mathrm{~mm}^{2}$; and (B) median and ulnar nerves at the axilla measuring $11 \mathrm{~mm}^{2}$ and $7 \mathrm{~mm}^{2}$, respectively.

\section{Patient and public involvement}

It was not possible to involve the patients or the public in the design, or conduct, or reporting or dissemination plans of our research.

\section{RESULTS}

Forty-one patients with SLE were found to be eligible for the study, of whom four were excluded (two died and two refused to perform the NCS). Moreover, two healthy subjects refused the NCS examination.

The baseline characteristics of both groups are shown in table 1 . There was no statistically significant difference in the mean values of age, height, weight, body mass index or gender between the two groups ( $>0.05)$. Fourteen patients $(37.8 \%)$ had clinical peripheral polyneuropathy manifestations (paresthesia, allodynia or hyperalgesia, numbness, burning and tingling). Thirty-six patients had asymmetrical polyneuropathy (according to NCS). Of them, $29(80.6 \%)$ had mixed polyneuropathy, $7(19.4 \%)$ had sensory polyneuropathy while only 1 $(2.7 \%)$ showed electrical changes of mononeuritis multiplex. The number of individual nerve affection based on patients' clinical examination is also listed in table 1.

On electrophysiological study, Student's t-test revealed the presence of a statistically significant difference
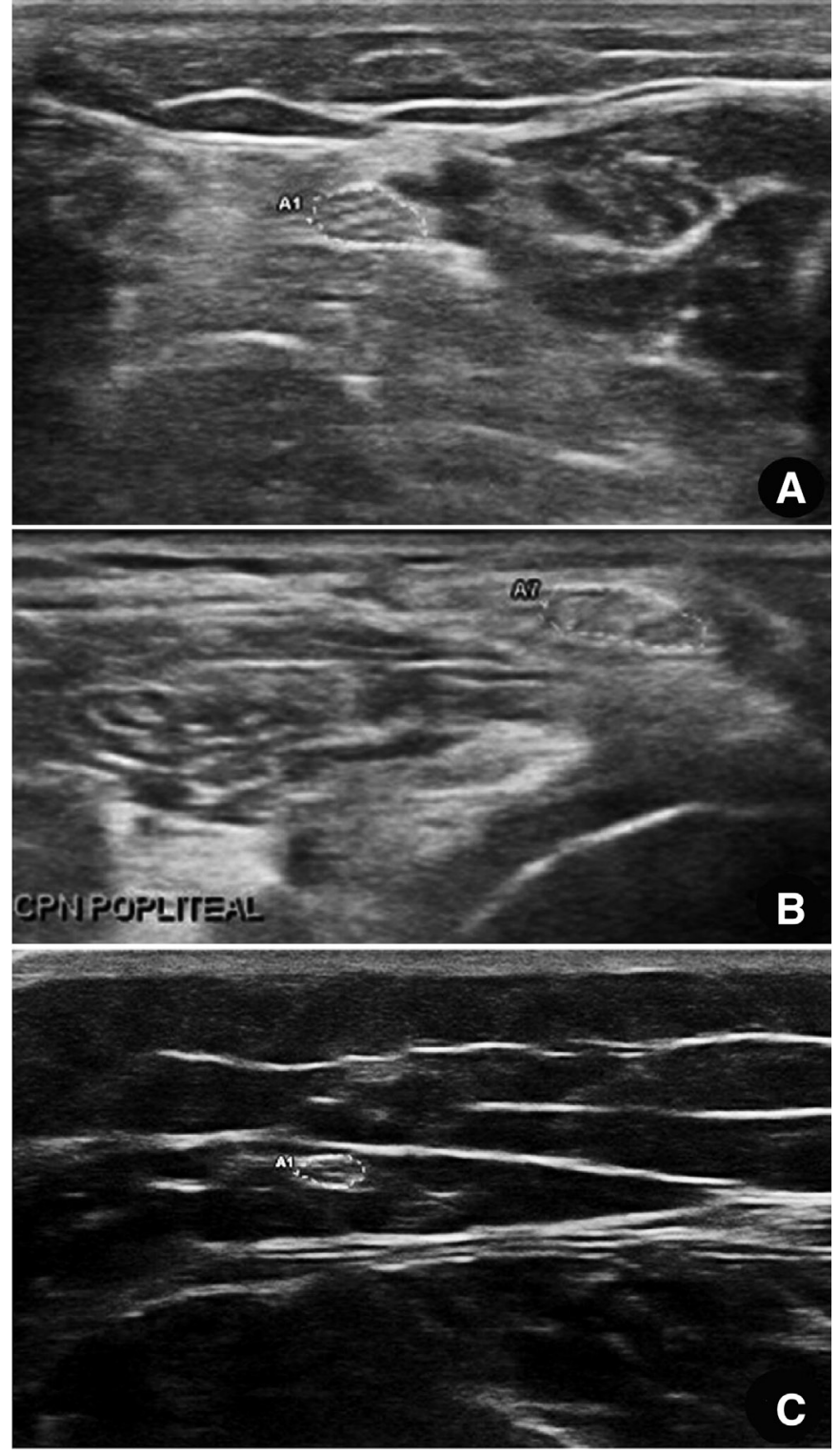

Figure 2 Neuromuscular ultrasonography showing axial views and cross-sectional area of the examined nerves: (A) tibial nerve at the distal leg measuring $8 \mathrm{~mm}^{2}$; (B) common peroneal nerve at the popliteal space measuring $12 \mathrm{~mm}^{2}$; and (C) sural nerve $14 \mathrm{~cm}$ proximal to the lateral malleolus level measuring $3 \mathrm{~mm}^{2}$.

between patients with SLE and healthy controls regarding all the NCS parameters, except the compound muscle action potential (CMAP) amplitude of the ulnar and popliteal nerves, F-wave latency of the tibial nerve, and motor conduction velocity of the popliteal nerve when stimulated at the ankle $(\mathrm{p}=0.144, \mathrm{p}=0.219, \mathrm{p}=0.600$ and $\mathrm{p}=0.970$, respectively) (table 2 ).

Both axonal and demyelinating nerve affections were observed. According to electrophysiological studies, the upper limb nerves were the most affected (median and ulnar, respectively), while the lower limb nerves were less commonly affected (sural, tibial and peroneal in order). Besides, axonal neuropathy was more prevalent in the upper limbs, and demyelinating neuropathy in the lower 
Table 1 Demographic and clinical data of the studied groups

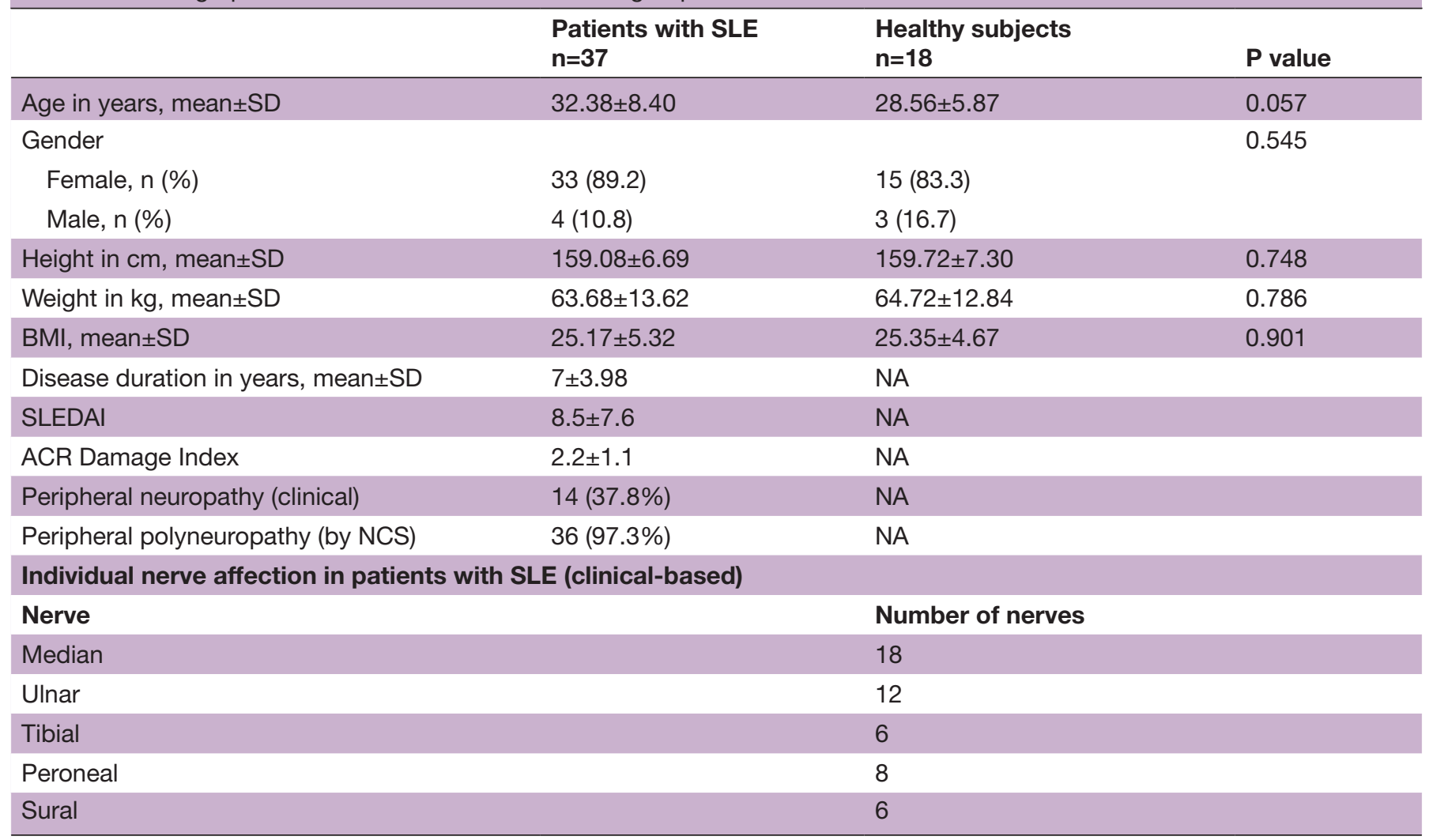

Student's t-test and $\chi^{2}$ were applied when appropriate.

BMI, body mass index; $n$, number of subjects; NA, not applicable; NCS, nerve conduction study; ACR NPSLE, American College of

Rheumatology; SLEDAI, Systemic Lupus Erythematosus Disease Activity Index.

limbs (table 3). The studied nerves were then divided into two groups: group A, which included the examined nerves in patients with SLE; and group B, which included the examined nerves of 18 healthy subjects. Depending on the results of NCS, group A nerves were further divided into group A1, which included nerves with normal NCS; and group A2, which included nerves with abnormal NCS. We examined a total of 1650 sites (1110 in 37 patients and 30 sites in 18 healthy subjects), and the mean CSA of each nerve at different sites was recorded in the studied groups (table 3). Significant CSA enlargement was found in group B as compared with the other two groups at the ulnar nerve at two sites, at Guyon's canal $(p=0.001)$ and at the mid-humerus $(p=0.001)$, in addition to the tibial nerve at the distal leg $(\mathrm{p}=0.003)$ and at the tarsal tunnel $(p=0.001)$, and finally in group A1 peroneal nerve at the popliteal fossa $(p=0.042)$ as compared with the other two groups. Furthermore, significant CSA enlargement was only described at the popliteal fossa in the tibial axonal and peroneal demyelinating neuropathies $(\mathrm{p}=0.020$ and $\mathrm{p}=0.026$, respectively) (table 3 ).

Using the mean CSA $+2 \mathrm{SD}$ of healthy subjects as a cut-off value and the NCS as a gold standard, the sensitivity and specificity of the NMUS measured CSA were estimated (ROC curve and cross-tabulation) and showed low sensitivity in all examined sites, in contrast to high specificity, although with low AUC (area under the ROC curve) and insignificant p value (table 4 ).

\section{DISCUSSION}

Our data show that the sonographically measured CSA of the peripheral nerves might be a helpful supplementary test to NCS in diagnosing PN in patients with SLE.

SLE-related peripheral nervous system (PNS) involvement is challenging for both rheumatologists and neurologists. In the last decade, many studies ${ }^{16-19}$ have focused on estimating the prevalence of PNS affection among patients with SLE, aiming to answer the question of whether it is caused by the disease or not. In our study, by clinical examination, $\mathrm{PN}$ was diagnosed in $37.8 \%$ of patients compared with $97.3 \%$ when diagnosed by NCS. This discrepancy may be attributed to the well-known high sensitivity, reliability and detective power of EDX versus clinical diagnosis. ${ }^{20}$

Recent advances in the field of NMUS have inspired us to use it in studying the peripheral nerve affection in patients with SLE and to find out if NMUS can be used as an alternative or at least complementary diagnostic tool to EDX, which is yet considered the gold standard in the detection of PN.

Variation in size of the involved nerves is one of the commonly encountered sonographic features in different 
Table 2 Results of nerve conduction study in the studied groups

\begin{tabular}{|c|c|c|c|c|}
\hline Examined nerve & NCS item & $\begin{array}{l}\text { Studied nerves in the SLE } \\
\text { group } \\
\mathrm{n}=74(\text { mean } \pm S D)\end{array}$ & $\begin{array}{l}\text { Healthy subjects } \\
\mathrm{n}=36 \text { (mean } \pm \text { SD) }\end{array}$ & $P$ value \\
\hline \multirow[t]{6}{*}{ Median } & MDL & $3.43 \pm 0.42$ & $3.21 \pm 0.26$ & 0.006 \\
\hline & MAmp & $11.40 \pm 4.37$ & $13.38 \pm 3.52$ & 0.020 \\
\hline & MNCV & $60.93 \pm 7.90$ & $70.83 \pm 5.96$ & 0.000 \\
\hline & SDL & $2.94 \pm 0.47$ & $2.30 \pm 0.21$ & 0.000 \\
\hline & SNCV & $48.94 \pm 7.92$ & $61.16 \pm 5.99$ & 0.000 \\
\hline & F-wave latency & $25.21 \pm 1.93$ & $23.68 \pm 1.54$ & 0.000 \\
\hline \multirow[t]{4}{*}{ Ulnar } & MDL & $2.76 \pm 0.38$ & $2.56 \pm 0.30$ & 0.004 \\
\hline & MAmp & $9.51 \pm 2.46$ & $8.76 \pm 2.58$ & 0.144 \\
\hline & SNCV & $55.72 \pm 8.84$ & $68.82 \pm 6.86$ & 0.000 \\
\hline & F-wave latency & $26.03 \pm 2.04$ & $24.94 \pm 1.64$ & 0.026 \\
\hline \multirow[t]{4}{*}{ Tibial } & MDL & $4.91 \pm 1.13$ & $3.52 \pm 0.59$ & 0.000 \\
\hline & MAmp & $11.41 \pm 5.37$ & $14.86 \pm 5.72$ & 0.003 \\
\hline & MNCV & $41.44 \pm 7.66$ & $48.76 \pm 4.54$ & 0.000 \\
\hline & F-wave latency & $46.99 \pm 7.12$ & $45.38 \pm 2.66$ & 0.600 \\
\hline \multirow[t]{3}{*}{ Peroneal } & MDL & $3.98 \pm 0.82$ & $3.53 \pm 0.58$ & 0.005 \\
\hline & MAmp & $4.75 \pm 2.93$ & $5.43 \pm 2.68$ & 0.219 \\
\hline & MNCV1 & $47.51 \pm 6.30$ & $53.93 \pm 6.37$ & 0.000 \\
\hline
\end{tabular}

Student's t-test was applied.

Amp, amplitude; DL, distal latency; MAmp, motor amplitude; MDL, motor distal latency; MNCV1, common peroneal nerve motor nerve conduction velocity stimulation at the ankle; MNCV2, common peroneal nerve conduction velocity stimulation at the fibular neck head; MNCV, motor nerve conduction velocity; n, number of each nerve examined; NCS, nerve conduction studies; NCV, nerve conduction velocity; SAmp, sensory amplitude; SDL, sensory distal latency; SNCV, sensory nerve conduction velocity.

types of nerve affection (hereditary or acquired polyneuropathy, entrapment neuropathy, nerve tumours, etc), based on the anatomical fact that the size of extremity nerves gets smaller along their course from proximal to distal. $^{712132122}$ Currently, CSA is considered a suitable and reliable quantitative parameter for evaluating changes in such nerves' sizes. ${ }^{23} 24$

Almost all our patients (97.3\%) had polyneuropathy as diagnosed by NCS. This agrees with many studies that described the peripheral polyneuropathy as the most frequent subtype of PN. ${ }^{16} 171925$ On the other hand, Oomatia and colleagues ${ }^{18}$ found 'small fiber neuropathy' to be the most prevalent type and drew the attention to some conditions not included in the American College of Rheumatology neuropsychiatric systemic lupus erythematosus (ACR NPSLE) case definition..$^{15}$ Some papers suggested the revision of ACR NPSLE 1999 case definition to consider some overlocked PN types like small fibre neuropathy. ${ }^{14-1925}$

Despite considering axonal neuropathy as the predominant polyneuropathy subtype in patients with SLE, ${ }^{16-1925}$ our results revealed a dominance of axonal involvement in upper limbs' nerves and a dominance of demyelinating neuropathy among lower limbs' nerves, which could be explained by the different pathogeneses in different types of SLE-related polyneuropathy. ${ }^{14} 16$ The limited number of patients included in this study could be another cause.

We were expecting that the axonal degeneration of the median and ulnar nerves was preceded by initial demyelination due to the prescribed lupus-induced entrapment caused by nearby arthritis and/or tenosynovitis, lupus nephritis, or idiopathic PNS lupus-related pathogenesis. ${ }^{16} 1925$ However, our data did not show any clinical or electrical findings suggestive of entrapment neuropathy. 
Table 3 Nerve CSA in the study population

\begin{tabular}{|c|c|c|c|c|c|c|c|c|}
\hline \multirow[b]{2}{*}{ Examinednerve } & \multirow[b]{2}{*}{$\begin{array}{l}\text { Measuring } \\
\text { site }\end{array}$} & \multirow[b]{2}{*}{$\begin{array}{l}\text { Group A1 } \\
\text { nerves } \\
\text { (CSA } \\
\text { mean } \pm S D \text { ), } \\
\text { mm }^{2}\end{array}$} & \multirow[b]{2}{*}{$\begin{array}{l}\text { Group A2 } \\
\text { nerves } \\
\text { (CSA } \\
\text { mean } \pm S D), \\
\text { mm }^{2}\end{array}$} & \multirow{2}{*}{$\begin{array}{l}\text { Group B } \\
\text { nerves } \\
\text { (CSA } \\
\text { mean } \pm S D), \\
\text { mm }^{2}\end{array}$} & \multirow[b]{2}{*}{ P1 value } & \multicolumn{2}{|c|}{ Group A2 nerves } & \multirow[b]{2}{*}{$\begin{array}{l}\mathrm{P} 2 \\
\text { value }\end{array}$} \\
\hline & & & & & & $\begin{array}{l}\text { Axonal } \\
\text { (CSA } \\
\text { mean } \pm S D), \\
\mathrm{mm}^{2}\end{array}$ & $\begin{array}{l}\text { Demyelinating } \\
\text { (CSA } \\
\text { mean } \pm S D), \\
\mathrm{mm}^{2}\end{array}$ & \\
\hline \multirow[t]{4}{*}{ Median } & & $n=13$ & $n=61$ & $n=36$ & & $n=50$ & $n=11$ & \\
\hline & CT & $8.0 \pm 2.1$ & $9.2 \pm 3.1$ & $9.0 \pm 1.6$ & 0.167 & $9.3 \pm 3.1$ & $8.9 \pm 3.4$ & 0.664 \\
\hline & $\mathrm{MH}$ & $8.1 \pm 3.0$ & $8.0 \pm 2.1$ & $8.5 \pm 1.7$ & 0.491 & $8.1 \pm 2.1$ & $7.7 \pm 2.3$ & 0.691 \\
\hline & $A X$ & $11 \pm 3.5$ & $9.2 \pm 3.3$ & $9.9 \pm 2.1$ & 0.112 & $9.3 \pm 3.5$ & $8.7 \pm 2.4$ & 0.895 \\
\hline \multirow[t]{2}{*}{ Ulnar } & & $\mathrm{n}=14$ & $n=60$ & $n=36$ & & $n=51$ & $n=9$ & \\
\hline & GY & $4.7 \pm 1.1$ & $5.1 \pm 1.3$ & $6.0 \pm 1.1$ & $0.001^{*}$ & $5.1 \pm 1.3$ & $5.0 \pm 1.5$ & 0.677 \\
\hline \multirow[t]{4}{*}{ Tibial } & & $n=35$ & $n=39$ & $n=36$ & & $n=10$ & $n=29$ & \\
\hline & POP & $19 \pm 4.9$ & $21 \pm 6.3$ & $21 \pm 6.0$ & 0.593 & $24 \pm 4.8$ & $20 \pm 6.4$ & $0.020^{*}$ \\
\hline & $\mathrm{DL}$ & $8.4 \pm 2.7$ & $9.4 \pm 3.6$ & $11 \pm 2.3$ & $0.009^{*}$ & $11 \pm 3.7$ & $8.9 \pm 3.6$ & 0.144 \\
\hline & $\pi$ & $8.6 \pm 2.8$ & $9.2 \pm 3.3$ & $11 \pm 2.8$ & $0.0001^{*}$ & $10 \pm 3.5$ & $8.9 \pm 3.2$ & 0.382 \\
\hline \multirow[t]{4}{*}{ Peroneal } & & $n=48$ & $n=26$ & $n=36$ & & $n=6$ & $n=20$ & \\
\hline & POP & $15 \pm 4.3$ & $14 \pm 4.8$ & $14 \pm 4.4$ & $0.042^{*}$ & $11 \pm 2.1$ & $15 \pm 5.1$ & $0.026^{\star}$ \\
\hline & $\mathrm{FN}$ & $16 \pm 6.2$ & $16 \pm 6.0$ & $15 \pm 4.7$ & 0.737 & $14 \pm 3.1$ & $16 \pm 6.7$ & 0.464 \\
\hline & DPN & $2.4 \pm 0.010$ & $2.2 \pm 1.0$ & $2.3 \pm 1.0$ & 0.554 & $2.2 \pm 0.98$ & $2.2 \pm 0.67$ & 0.742 \\
\hline Sural & & $n=24$ & $n=50$ & $n=36$ & & $n=21$ & $n=29$ & \\
\hline
\end{tabular}

Group A1: nerves with normal NCS in patients with SLE; group A2: SLE nerves with abnormal NCS in patients with SLE; group B: nerves of healthy subjects (with normal NCS).

P1: one-way analysis of variance test was used; P2: Student's t-test was used.

${ }^{*} \mathrm{P}<0.05$ is significant.

AX, axilla; CSA, cross-sectional area; CT, carpal tunnel inlet; DL, distal leg ( $5 \mathrm{~cm}$ above medial malleolus); DPN, deep peroneal nerve at anterior aspect of the ankle; FN, fibular neck; GY, Guyon's canal; MF, mid-forearm; MH, mid-humerus; n, number of nerves; NCS, nerve conduction study; POP, popliteal fossa; $\Pi$, tarsal tunnel.

On NMUS examination of each nerve at certain sites between the studied groups, the following were noted:

- The mean CSA of the tibial nerve at the distal leg in the patient group was significantly smaller than the CSA in normal subjects, which may be supported by the 'dying back' theory of long-standing immunemediated nerve injury occurring in lupus that eventually leads to axon loss. ${ }^{11} 1225$

- Among patients with SLE who have abnormal NCS, the mean CSA was significantly large in axonal tibial neuropathy and demyelinating peroneal neuropathy (both at the popliteal fossa). Grimm et $\mathrm{al}^{1314}$ suggested that axonal neuropathy causes non-significant enlargement when compared with demyelinating.

- The mean CSA of the median nerve distally at the carpal tunnel was larger than its proximal segment in the mid-forearm among all groups, especially both nerves of healthy subjects and those with normal NCS in patients with SLE. This was also found in both the ulnar (at Guyon's canal) and tibial (at the tarsal tunnel) nerves, but with the CSA in the healthy group significantly larger than both in the patient group. In concordance with this finding, Zaidman et $a l^{21}$ assumed that even normal nerves at the entrapment area are likely to be larger in size than its proximal segment.

The differences in nerves' CSA between the studied groups and along the course of the same nerve were statistically non-significant. Many authors found no correlation between CSA, electrophysiological and clinical findings, and functional disabilities. ${ }^{121325}$

The ROC curve analyses showed that of all the CSA measuring points, the median nerve at the mid-forearm has the best diagnostic power, where AUC was 0.579 and specificity was $95.9 \%$, followed by ulnar nerve at the axilla and the fibular nerve at the fibular neck, with AUC of 0.545 and 0.544 , respectively. 
Table 4 Sensitivity and specificity of the nerve cross-sectional area in relation to the nerve conduction study results in all studied nerves

\begin{tabular}{|c|c|c|c|c|c|c|c|}
\hline Nerves & Measuring site & Sensitivity (\%) & Specificity (\%) & $\begin{array}{l}\text { Positive } \\
\text { predictive } \\
\text { value (\%) }\end{array}$ & $\begin{array}{l}\text { Negative } \\
\text { predictive } \\
\text { value (\%) }\end{array}$ & $\begin{array}{l}\text { Area under } \\
\text { the curve }\end{array}$ & $P$ value \\
\hline \multirow[t]{4}{*}{ Median } & СT & 18.0 & 95.9 & 84.6 & 48.5 & 0.514 & 0.796 \\
\hline & MF & 3.3 & 95.9 & 50.0 & 44.3 & 0.579 & 0.157 \\
\hline & $\mathrm{MH}$ & 3.3 & 95.9 & 50.0 & 44.3 & 0.451 & 0.378 \\
\hline & $A X$ & 11.5 & 93.9 & 70.0 & 46.0 & 0.385 & 0.038 \\
\hline \multirow[t]{4}{*}{ Ulnar } & GY & 1.7 & 100.0 & 100.0 & 45.9 & 0.375 & 0.025 \\
\hline & MF & 6.7 & 96.0 & 66.7 & 46.2 & 0.471 & 0.606 \\
\hline & MA & 3.3 & 96.0 & 50.0 & 45.3 & 0.466 & 0.536 \\
\hline & $A X$ & 5 & 98 & 75 & 46.2 & 0.544 & 0.433 \\
\hline \multirow[t]{3}{*}{ Tibial } & POP & 7.7 & 98.0 & 75.0 & 66.0 & 0.536 & 0.532 \\
\hline & $\mathrm{DL}$ & 10.3 & 98.6 & 80.0 & 66.7 & 0.454 & 0.429 \\
\hline & $\pi$ & 2.6 & 97.2 & 33.3 & 64.5 & 0.412 & 0.129 \\
\hline \multirow[t]{3}{*}{ Peroneal } & POP & 7.7 & 91.7 & 22.2 & 76.2 & 0.439 & 0.349 \\
\hline & FNB & 11.5 & 95.2 & 42.9 & 77.7 & 0.545 & 0.493 \\
\hline & DPN & 0.0 & 97.6 & 0.0 & 75.9 & 0.443 & 0.383 \\
\hline Sural & & 4.0 & 96.7 & 50.0 & 54.7 & 0.530 & 0.585 \\
\hline
\end{tabular}

AX, axial; CT, carpal tunnel inlet; DPN, deep peroneal nerve; FNB, fibular neck bone; GY, Guyon's canal; MA, mid arm; MF, mid-forearm; MH, mid-humerus; POP, popliteal; TT, tarsal tunnel.

Interestingly, all the examined sites of the 370 studied nerves showed low sensitivity values $(<50 \%)$. On the other hand, the specificity values were remarkably high and reached up to $98.6 \%$ in some examination points.

The strength point of this study is being the first study carried out to evaluate SLE-related neuropathy using NMUS. Some of the strict methodology outlines could be considered as points of strength, for instance, the application of extensive exclusion criteria to sort out coincidental causes of neuropathy other than SLE and subsequently overcome any possible interference with the outcomes. Additionally, the use of healthy age-matched and sexmatched control subjects of the same ethnicity was to reduce any probable divergence in NCS or in NMUS value that might affect our analysis. Another strength point is the performance of both NCS and NMUS examinations on the same day for a more accurate analysis of the results.

Furthermore, the NMUS images were evaluated by three different expert rheumatologists who were blinded to clinical and electrophysiological results to guarantee agreement and an unbiased decision on the findings.

Although the sample size seems to be relatively small, we examined 1164 sites in both the patients and in healthy subjects, which gave relatively large data used in statistics.

Moreover, one of the strengths was the absence of clinical and electrophysiological evidence of entrapment neuropathy, which highly suggested the possible presence of different mechanisms of SLE-related neuropathy in comparison with other types of neuropathies.
Our study has some limitations, including being a single-centre study with a relatively small sample size (the minimum possible according to the sample size calculation software), which resulted in the inability to apply patient randomisation. We recommend future multicentre study to develop a nation-based reference values of the CSA of different nerves. Another recommendation is to study other nerve parameters such as echogenicity, mobility and vascularity, in addition to CSA, while examining the peripheral nerves using NMUS.

\section{CONCLUSION}

To our knowledge, this is the first study that used NMUS in investigating peripheral nerve involvement in patients with SLE. Although the changes in nerve size were not pronounced, the CSA of individual nerves might provide informative data on possible different pathophysiological aspects of nerve disease in patients with SLE. Further validation in larger cohorts of patients is recommended.

\section{Author affiliations}

${ }^{1}$ Department of Rheumatology, Rehabilitation and Physical Medicine, Assiut University, Assiut, Egypt

${ }^{2}$ Medical-Geriatric Department, Azienda Ospedaliero Universitaria Careggi, Firenze, Italy

${ }^{3}$ MoMaRC Morphological Madrid Research Center, Ultradissection group, Madrid, Spain

${ }^{4}$ Department of Physical Medicine, Rheumatology and Rehabilitation, Tanta University Faculty of Medicine, Tanta, Egypt

${ }^{5}$ Division of Rheumatology, Hospital Universitario del Tajo, Aranjuez, Spain 
${ }^{6}$ Department of Public Health and Community, Faculty of Medicine, Assiut University, Assiut, Egypt

${ }^{7}$ Division of Rheumatology, Department of Experimental and Clinical Medicine, University of Florence, Firenze, Italy

Contributors SAM: planning, shared in conducting the work, revising and editing the manuscript. FG: writing and editing the manuscript. TMK: supervising the workflow and revising the manuscript. AE: planning, conducting the work and cowriting. AA: cowriting and revising the manuscript. AGM: revising the manuscript. DMM0: performed the statistical study. MM-C: cowriting and revising the manuscript. SG: revising the manuscript. MAAG: planning, shared in conducting the work, cowriting and revising the manuscript.

Funding The authors have not declared a specific grant for this research from any funding agency in the public, commercial or not-for-profit sectors.

Competing interests None declared.

Patient and public involvement Patients and/or the public were not involved in the design, or conduct, or reporting, or dissemination plans of this research.

Patient consent for publication Not required.

Ethics approval This study was approved by the Committee of Medical Ethics of the Faculty of Medicine of our university, following the Declaration of Helsinki (IRB no 17200346).

Provenance and peer review Not commissioned; externally peer reviewed. Data availability statement All data relevant to the study are included in the article or uploaded as supplementary information.

Open access This is an open access article distributed in accordance with the Creative Commons Attribution Non Commercial (CC BY-NC 4.0) license, which permits others to distribute, remix, adapt, build upon this work non-commercially, and license their derivative works on different terms, provided the original work is properly cited, appropriate credit is given, any changes made indicated, and the use is non-commercial. See: http://creativecommons.org/licenses/by-nc/4.0/.

ORCID iDs

Felice Galluccio http://orcid.org/0000-0001-7485-471X

Marco Matucci-Cerinic http://orcid.org/0000-0002-9324-3161

\section{REFERENCES}

1 Hanly JG, McCurdy G, Fougere L, et al. Neuropsychiatric events in systemic lupus erythematosus: Attribution and clinical significance. $J$ Rheumatol 2004;31:2156-62.

2 Rees F, Doherty M, Grainge MJ, et al. The worldwide incidence and prevalence of systemic lupus erythematosus: a systematic review of epidemiological studies. Rheumatology 2017;56:1945-61.

3 The American College of rheumatology Nomenclature and case definitions for neuropsychiatric lupus syndromes. Arthritis Rheum 1999;42:599-608.

4 Petri M, Orbai A-M, Alarcón GS, et al. Derivation and validation of the systemic lupus international collaborating clinics classification criteria for systemic lupus erythematosus. Arthritis Rheum 2012;64:2677-86.

5 Kerasnoudis A, Tsivgoulis G. Nerve ultrasound in peripheral neuropathies: a review. J Neuroimaging 2015;25:528-38.

6 Gallardo E, Noto Y-I, Simon NG, Y-i N, NGJJoN S. Ultrasound in the diagnosis of peripheral neuropathy: structure meets function in the neuromuscular clinic. J Neurol Neurosurg Psychiatry
7 Telleman JA, Grimm A, Goedee S, et al. Nerve ultrasound in polyneuropathies. Muscle Nerve 2018;57:716-28.

8 Telleman JA, Herraets IJT, Goedee HS, et al. Nerve ultrasound. Neurology 2019;92:e443-50.

9 Wu W-T, Chen L-R, Chang H-C, et al. Quantitative ultrasonographic analysis of changes of the suprascapular nerve in the aging population with shoulder pain. Front Bioeng Biotechnol 2021;9:121.

10 Chang P-H, Chen Y-J, Chang K-V. Ultrasound measurements of superficial and deep masticatory muscles in various postures: reliability and influencers. Sci Rep 2020;10:1-9.

11 Zaidman CM, Seelig MJ, Baker JC, et al. Detection of peripheral nerve pathology: comparison of ultrasound and MRI. Neurology 2013;80:1634-40.

12 Kerasnoudis A, Woitalla D, Gold R, et al. Sarcoid neuropathy: correlation of nerve ultrasound, electrophysiological and clinical findings. J Neurol Sci 2014;347:129-36.

13 Grimm A, Décard BF, Bischof A, et al. Ultrasound of the peripheral nerves in systemic vasculitic neuropathies. $J$ Neurol Sci 2014;347:44-9.

14 Grimm A, Heiling B, Schumacher U, et al. Ultrasound differentiation of axonal and demyelinating neuropathies. Muscle Nerve 2014;50:976-83.

15 Varma SJM nervePreston DC, Shapiro BE, eds. Electromyography and neuromuscular disorders: Clinical-electrophysiologic correlations. . Elsevier Saunders, 2012: 48. 308.

16 Florica B, Aghdassi E, Su J, eds. Peripheral neuropathy in patients with systemic lupus erythematosus. Seminars in arthritis and rheumatism. Elsevier, 2011.

17 Unterman A, Nolte JE, Boaz M, eds. Neuropsychiatric syndromes in systemic lupus erythematosus: a meta-analysis. Seminars in arthritis and rheumatism. Elsevier, 2011.

18 Oomatia A, Fang H, Petri M, et al. Peripheral neuropathies in systemic lupus erythematosus: clinical features, disease associations, and immunologic characteristics evaluated over a twenty-five-year study period. Arthritis Rheumatol 2014;66:1000-9.

19 Toledano P, Orueta R, Rodríguez-Pintó I, et al. Peripheral nervous system involvement in systemic lupus erythematosus: prevalence, clinical and immunological characteristics, treatment and outcome of a large cohort from a single centre. Autoimmun Rev 2017;16:750-5.

20 England JD, Gronseth GS, Franklin G. Distal symmetrical polyneuropathy: a definition for clinical research. A report of the American Academy of Neurology, the American association of Electrodiagnostic medicine, and the American Academy of physical medicine and rehabilitation. Neurology 2005;86:167-74.

21 Zaidman CM, Al-Lozi M, Pestronk A. Peripheral nerve size in normals and patients with polyneuropathy: an ultrasound study. Muscle Nerve 2009;40:960-6.

22 Kerasnoudis A, Pitarokoili K, Behrendt V, et al. Correlation of nerve ultrasound, electrophysiological and clinical findings in chronic inflammatory demyelinating polyneuropathy. $J$ Neuroimaging 2015;25:207-16.

23 Cartwright MS, Passmore LV, Yoon J-S, et al. Cross-Sectional area reference values for nerve ultrasonography. Muscle Nerve 2008;37:566-71.

24 Tagliafico A, Cadoni A, Fisci E, et al. Reliability of side-to-side ultrasound cross-sectional area measurements of lower extremity nerves in healthy subjects. Muscle Nerve 2012;46:717-22.

25 Bortoluzzi A, Silvagni E, Furini F. Peripheral nervous system involvement in systemic lupus erythematosus: a review of the evidence 2019;37:146-55. 